Erratum

\title{
Erratum to "Online Learning Resources Enhanced Teaching and Learning of Medical Mycology among Medical Students in Gulu University, Uganda”
}

\author{
Felix Bongomin $\mathbb{D}^{1},{ }^{1,2}$ Bernard Erima, ${ }^{1}$ Richard Kwizera $\mathbb{D D}^{3},{ }^{3}$ Emmanuel I. Odongo-Aginya, ${ }^{1}$ \\ and David W. Denning ${ }^{2,4}$ \\ ${ }^{1}$ Department of Medical Microbiology \& Immunology, Faculty of Medicine, Gulu University, Gulu, Uganda \\ ${ }^{2}$ Global Action Fund for Fungal Infections (GAFFI), Geneva, Switzerland \\ ${ }^{3}$ Infectious Diseases Institute, College of Health Sciences, Makerere University, Kampala, Uganda \\ ${ }^{4}$ National Aspergillosis Centre, ECMM Centre of Excellence in Clinical and Laboratory Mycology and Clinical Studies, \\ Wythenshawe Hospital, Manchester University NHS Foundation Trust, Manchester, UK
}

Correspondence should be addressed to Felix Bongomin; felix.ayoli9@gmail.com

Received 29 April 2020; Accepted 29 April 2020; Published 12 May 2020

Copyright (c) 2020 Felix Bongomin et al. This is an open access article distributed under the Creative Commons Attribution License, which permits unrestricted use, distribution, and reproduction in any medium, provided the original work is properly cited.

In the article titled "Online Learning Resources Enhanced Teaching and Learning of Medical Mycology among Medical Students in Gulu University, Uganda" [1], David W. Denning was missing from the authors' list. The corrected authors' list is shown above.

\section{References}

[1] F. Bongomin, B. Erima, R. Kwizera, and E. I. Odongo-Aginya, "Online learning resources enhanced teaching and learning of medical mycology among medical students in Gulu University, Uganda," Education Research International, vol. 2020, Article ID 9468241, 5 pages, 2020 . 